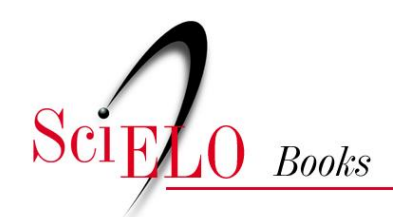

\title{
2 - Formação para a docência na educação online
}

\author{
Taíses Araújo da Silva Alves \\ Robson Pequeno de Sousa
}

\section{SciELO Books / SciELO Livros / SciELO Libros}

ALVES, TAS., and SOUSA, RP. Formação para a docência na educação online. In: SOUSA, RP., et al., orgs. Teorias e práticas em tecnologias educacionais [online]. Campina Grande: EDUEPB, 2016,

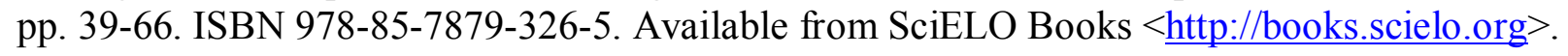

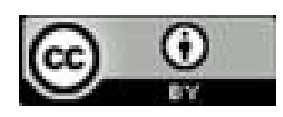

All the contents of this work, except where otherwise noted, is licensed under a Creative Commons Attribution $\underline{4.0 \text { International license. }}$

Todo o conteúdo deste trabalho, exceto quando houver ressalva, é publicado sob a licença Creative Commons Atribição 4.0.

Todo el contenido de esta obra, excepto donde se indique lo contrario, está bajo licencia de la licencia $\underline{\text { Creative }}$ Commons Reconocimento 4.0. 


\author{
Taíses Araújo da Silva Alves \\ Robson Pequeno de Sousa
}

\title{
INTRODUÇÃO
}

As instituições educacionais contemporâneas, frente às constantes transformações que vêm ocorrendo na nossa sociedade, principalmente no que concerne à presença das tecnologias da informação e comunicação, têm sido desafiadas a repensar sobre suas práticas. Dentre essas modificações, podemos citar as questões econômicas e culturais, que se desdobram em novas formas de apreensão espaço/temporal, no surgimento de novos postos de trabalho, na crise do conhecimento, na digitalização da informação e na emergência da cibercultura.

O desenvolvimento das Tecnologias Digitais de Informação e Comunicação (TDIC) e com elas o avanço da Educação Online constituem uma realidade que não pode ser ignorada na formação inicial ou continuada de professores, sob pena de se desconsiderar as mudanças dos meios de comunicação e a eficácia de sua aplicabilidade na sociedade, de modo geral, e na educação em particular.

Atualmente, uma das principais preocupações das pesquisas em $\mathrm{EaD}$ está no processo de aprender porque esse processo ganha 
um novo significado em função dos conhecimentos que terão de ser construídos e reconstruídos de forma constante pelos indivíduos, implicando no desenvolvimento de habilidades consideradas fundamentais para atuarem de forma efetiva na sociedade contemporânea.

A Educação Online traz consigo características próprias que impõem a necessidade de novas aprendizagens, o que implica na necessidade de que seja construída uma nova maneira de compreender o processo de ensino-aprendizagem.

Diante da fecundidade de discussões sobre as especificidades da atuação docente no contexto do ciberespaço, e considerando a demanda para a formação de educadores preparados para atuar neste novo paradigma educacional, surgem as seguintes questões: Como pensar ensino e aprendizagem nesse cenário? Como estruturar a docência preservando o protagonismo e a condição ativa do aprendiz e, ao mesmo tempo, proporcionar-lhe experiências significativas? Enfim, o que considerar numa formação de professores para o trabalho com Educação Online?

Nosso estudo trata-se de uma Pesquisa Qualitativa de caráter exploratório, constituindo uma elaboração teórica que busca refletir sobre a importância da formação continuada de docentes do Ensino Superior para atuar na Educação Online. Para consecução desse objetivo iremos: refletir sobre as mudanças no processo de ensino-aprendizagem na Educação a Distância com o advento das TDIC; investigar as especificidades da Educação Online, desenvolvida através de Ambientes Virtuais de Aprendizagem; compreender o papel do professor na Educação Online; tecer reflexões sobre alguns aspectos a serem considerados na formação dos professores para esta modalidade. 
O presente estudo está estruturado em seis partes, além desta Introdução. A primeira parte apresenta uma discussão sobre o processo de Ensino e Aprendizagem na Sociedade em Rede e os desafios da educação, advindos com a Sociedade da Informação. A segunda parte discute sobre a evolução da Educação a Distância e o advento da Educação Online. A terceira parte apresenta a metodologia de pesquisa. A quarta parte reflete sobre a formação dos professores para atuar na Educação Online, apresentando alguns aspectos a serem considerados quando do desenvolvimento de propostas formativas para os docentes que atuarão em ambientes virtuais e por fim as considerações finais e referências.

\section{TECNOLOGIAS E EDUCAÇÃO A DISTÂNCIA}

Desde os primórdios da sociedade, a tecnologia sempre afetou o homem: das primeiras ferramentas, por vezes consideradas extensões do corpo, à máquina a vapor, que mudou hábitos e instituições; ao computador, que trouxe novas e profundas mudanças sociais e culturais; às redes informáticas, que estão criando novas formas de relações humanas. Nesse sentido, a tecnologia ajuda, completa e amplia. Ora fascina, ora assusta.

Para Belloni (2002), o uso de uma tecnologia (no sentido de artefato técnico), em situação de ensino e aprendizagem, deve estar acompanhado de uma reflexão sobre a mesma (no sentido do conhecimento embutido no artefato e em seu contexto de produção e utilização), o que reforça a necessidade de assegurar sua dupla dimensão como ferramenta e objeto de estudo e reflexão. Isso significaria ser capaz de realizar um deslocamento de enfoques: do enfoque pragmático para um enfoque criativo. Para realizar tal deslocamento, seria 
necessário ir além das dualidades, construindo novos enfoques de natureza multidisciplinar.

Tal mudança de enfoque no uso das TDIC vem se desenvolvendo no mundo inteiro, desde os anos 70, de uma concepção instrumental de tecnologia educacional para uma concepção de comunicação educacional integradora que considere sua dupla dimensão (instrumental e conceitual; ética e estética). Trata-se de educação para as mídias, cujos objetivos dizem respeito à formação do usuário ativo, crítico e criativo de todas as tecnologias de informação e comunicação (BELLONI, 2002).

Cabe acrescentar, ainda, que é essencial ensinar-aprender a conviver com relações complexas geradas pela inserção da tecnologia na sociedade e espera-se que, no âmbito da educação, os novos modos de pensar possibilitam o diálogo entre o pensamento lógico e a sensibilidade, entre a sensação e a intuição.

Em EaD, a utilização dos meios técnicos não reduz os outros componentes do processo educativo (tanto os técnicos como os humanos) a algo secundário. Pelo contrário, estes meios são ferramentas para uma educação eficaz, sobretudo quando se trata de educação para um grande número de pessoas.

Atualmente, a tecnologia educacional está em função da intensificação do uso das Tecnologias de Informação e Comunicação (TIC). Comunicação e educação estão cada vez mais interdependentes, o que constitui para o educador um grande desafio na dimensão pedagógica de sua atividade técnico-científica.

A discussão em torno das TIC na educação não são necessariamente decorrentes da $\mathrm{EaD}$. O desenvolvimento da $\mathrm{EaD}$ e sua viabilidade é que estão historicamente ligados ao desenvolvimento das tecnologias, podendo ser identificadas diversas gerações de EaD, 
interligadas para promover o processo de interlocução entre alunos e professores: impressa, audiovisual e telemática.

\section{ENSINO E APRENDIZAGEM NA SOCIEDADE DA INFORMAÇÃO}

Durante as últimas décadas, as instituições educacionais vêm passando por um processo de mudança muito significativo, com destaque para o crescimento da Educação a Distância no processo educacional. Os paradigmas presentes na sociedade já não dão conta das relações, das necessidades e dos desafios sociais. Vive-se atualmente na 'Sociedade em Rede", uma sociedade que dá ênfase à cultura da aprendizagem, convergindo para a construção de um novo modelo (BEHAR, 2009).

Os novos sistemas de comunicação, advindos com a Sociedade da Informação, propiciam o surgimento de formas diferentes de conhecer e de estabelecer relações que permitem a expressão das ideias por meio de distintas linguagens e da construção do pensamento. O ciberespaço é o novo meio de comunicação onde se conectam os computadores e se abriga o mundo de informações, formando uma "rede"que permite às pessoas "navegar", disponibilizar suas ideias e trocar informações (LEVY, 1999).

A sociedade da informação, do conhecimento, da aprendizagem, em que vivemos, modifica a vida dos cidadãos em inúmeros planos, assim como os cenários, os meios de produção, o que repercute sobre os processos de aprender e de ensinar com tecnologias nas instituições de ensino superior - em tais cenários, reconfigurados pela acelerada evolução tecnológica, não há propostas únicas nem é desejável que se atenda a todos da mesma maneira, de modo que qualquer pro- 
posta de formação reveste-se de inquietudes trazidas pelos matizes e incertezas das novas e complexas possibilidades.

\section{DESAFIOS DA SOCIEDADE DA INFORMAÇÃO PARA A EDUCAÇÃO}

As transformações ocorridas na sociedade, em grande parte como decorrência dos avanços tecnológicos, produziram alterações profundas em todos os setores da vida humana, exigindo adaptações rápidas, que por sua vez requerem conhecimentos e habilidades distintos daqueles já consolidados. A rapidez no fluxo das informações, associada aos sofisticados meios de comunicação, coloca as pessoas diante de situações que desafiam a sua inteligência e suscitam novas aprendizagens. O conhecimento, elemento central para a organização e desenvolvimento da sociedade, é ao mesmo tempo o grande motivador e uma grande incógnita, dada a complexidade e provisoriedade.

As instituições educativas não conseguem dar conta de proporcionar toda a informação relevante e necessária para os estudantes, desta forma o mais importante é formar os aprendizes para terem acesso a ela na medida de suas necessidades, ou seja, prepará-los para continuarem aprendendo sempre. Educar, portanto, não pode implicar tão somente transmissão de informações, assegurando que elas sejam retidas na memória para serem utilizadas em outras oportunidades, uma vez que, a qualquer momento, elas poderão deixar de ser importantes e significativas. O que importa na verdade é que o aprendiz seja capaz de trabalhá-las de forma crítica, para poder utilizá-las na solução de problemas.

No bojo das mudanças tecnológicas, culturais e científicas não há como prever quais serão os conhecimentos necessários para 
viver em sociedade e inserir-se no mundo do trabalho daqui a alguns anos. Essas considerações sobre a aprendizagem tornam clara a ideia de que os aprendizes deverão ser preparados para gerir o processo de construção do conhecimento, aprendendo a aprender ao longo da vida.

Mudar as formas de aprender dos alunos requer também as formas de ensinar dos seus professores. Por isso, a nova cultura de aprendizagem exige um novo perfil de aluno e do professor, exige novas funções discentes e docentes, as quais só se tornarão possíveis se houver uma mudança de mentalidade (POZZO, 2004, p.11).

\section{NOVAS FORMAS DE APRENDER}

A sociedade, chamada por alguns pensadores de Sociedade da Informação, por outros de Sociedade do Conhecimento ou ainda Sociedade da Aprendizagem, caracteriza-se pela rapidez e abrangência de informações. A realidade do mundo atual requer um novo perfil de profissional e cidadão que coloca para as instituições educacionais novos desafios. No cotidiano, encontram-se situações que demandam o uso de novas tecnologias que provocam transformações na nossa maneira de pensar e de nos relacionarmos com as pessoas, com os objetos e com o mundo ao redor.

O desafio atual do sistema educacional é formar os alunos para a cidadania responsável e para que sejam contínuos aprendizes, que tenham autonomia na busca e seleção de informações para aprender a aprender ao longo da vida.

Os alunos precisam ser preparados para utilizar os sistemas culturais de representação do pensamento que marcam a sociedade contemporânea, o que implica em novas formas de letramento ou 
alfabetização (sonora, visual, hipermídia...) próprias da cibercultura, além das demais formas já conhecidas (SANTOS, 2005).

A exigência de aprender continuamente ao longo da vida constitui na sociedade atual um desafio para todas as pessoas e uma necessidade premente colocada aos educadores. Não se trata apenas de ter acesso a informações, mas sim de saber buscá-las em diferentes fontes e, sobretudo, transformar as informações em conhecimentos para resolver problemas da vida e do trabalho.

Integrando-se em redes de comunicação, os indivíduos acabam por tornar informação e conhecimento um bem comum e a produtividade intelectual artística e científica alcança dimensão universal: o conhecimento passa a pertencer a todos e todos podem utilizá-lo, de modo que a educação pode contribuir para redistribuir a riqueza do conhecimento e para o desenvolvimento pessoal (SILVA, 2003).

Garantido o acesso às informações, organizam-se redes de interação apoiadas nas tecnologias disponíveis, o que acaba por alterar forma e conteúdo do trabalho, provocando a renovação dos locais de trabalho e estudo (MELLO, 2003 apud PORTO, 2003). As TIC trazem novas formas de compreensão e expressão da realidade que de certa forma podem ser utilizadas para reprodução de mensagens ou interatividade, síncrona ou assíncrona.

No contexto da EaD online, o aluno pode estudar, interagir com outros alunos, professores, tutores e instituição, refletir e aprender em local e horário de sua escolha, bastando para isto ter acesso a um computador conectado à internet. Sobre isto, Silva (2003) afirma que a EaD online é uma exigência da cibercultura, isto é, do novo contexto socioeconômico-tecnológico. 


\section{NOVOS MODOS DE ENSINAR}

Diante dessa nova realidade do saber e do conhecimento veloz, provisório, dinâmico, o professor precisa redefinir o seu papel, rever seus paradigmas de aprendizagem e ensino, rever sua postura diante da realidade que o circunda e buscar novas alternativas para entrar em sintonia com o mundo contemporâneo que aí está e que exige dele uma redefinição da sua identidade profissional.

Na modalidade de Educação a Distância, a figura do professor não é eliminada. Ao contrário, passa a ser um elemento chave, porque sem ele os cursos oferecidos, através dessa modalidade de ensino, correm o risco de não formar, ou apenas informar o aluno sobre os conteúdos ofertados. A informação, pura e simples, pode ser apenas um adorno, uma estratégia para gerir o indivíduo no espaço social, mas, se não houver alguém que conduza um processo educativo, que mobilize e dinamize o acesso dessa informação, não haverá a produção e a criação do conhecimento desejado. É nesse ponto que a educação difere da informação. A educação propicia ao indivíduo o desenvolvimento do senso crítico, da capacidade de criar seu próprio saber, fundamental ao seu desenvolvimento social, cultural, ético e cidadão.

Segundo Santos (2005), as redes, não só de máquinas e de informação, mas principalmente de pessoas, tribos e comunidades, estão permitindo configurar novos espaços de interação e de aprendizagem. Tais possibilidades estão pondo, em xeque, o papel e o "poder centralizador" dos professores na contemporaneidade. Não há mais emissores (professores) e receptores (estudantes) como dois grupos distintos com mensagens estáticas e, sim, um grande grupo interagindo que pode constantemente reconstruir conhecimentos. 
A formação de comunidades cooperativas de trabalho e aprendizagem em rede, presenciais e/ou virtuais, fica favorecida e elas podem influir sobre o aprender e se disseminar na sociedade, incorporando novos participantes, reflexões e contribuições. Desafia os professores a enfrentar novas responsabilidades diante das crises provocadas pela globalização, educar em valores e construir personalidades flexíveis e eticamente desenvolvidas passa a ser fundamental (CASTELLS, 1999), assim como superar propostas de educação baseadas na transmissão de pacotes de conhecimentos sistematizados que proporcionam educação bancária, empobrecedora da formação, da atuação profissional e da participação social (FREIRE,1969).

A despeito do espaço e do tempo, pessoas podem colaborar, reforçar laços de afinidade e se constituírem como comunidades. Qualquer sujeito de qualquer ponto pode não só trocar informações, mas reconstruir significados, rearticular idéias individual e coletivamente, e assim partilhar novos sentidos com todos os usuários da rede, do ciberespaço (SANTOS, 2005, p.18).

O ciberespaço é composto por uma diversidade de elementos constitutivos, interfaces que permitem diversos modos de comunicação: um-um, um-todos e todos-todos em troca simultânea (comunicação síncrona) ou não (comunicação assíncrona) de mensagens. Tais possibilidades podem implicar mudanças diretas, nem melhores nem piores, mas diferentes, na forma e no conteúdo das relações de aprendizagem do coletivo. É através do conjunto de interfaces que os usuários interagem com a máquina e com outros usuários, compondo assim o ciberespaço e a cibercultura.

O ciberespaço é concebido e estruturado de modo a ser, antes de tudo, um espaço social de comunicação e de trabalho em grupo. Portanto, o saber já não é mais o produto pré-construído e "midiaticamen- 
te" difundido, mas o resultado de um trabalho de construção individual ou coletivo a partir de informações ou situações midiaticamente concebidas para oferecer ao aluno ou ao estudante oportunidades de mediação (ALAVA, 2002, p.14).

Como consequência do contexto de redefinição da postura docente, em função da demanda tecnológica, surge a necessidade de preparar professores para atuar, com essas tecnologias, como mediador desse novo processo educativo. Segundo Niskier (2000):

A educação, como um todo, não pode ser operacionalizada sem pessoal competente. Qualquer tentativa de melhoria do sistema pedagógico não prescinde da ação do professor. Em última análise, é ao professor que cabe transformar qualquer nova proposta em uma ação pedagógica competente (NISKIER, 2000, p.26).

$\mathrm{Na}$ identificação e formação desses profissionais, devem ser consideradas as condições intelectuais e humanas necessárias ao desempenho do seu novo papel que é o de orientar os estudos e a aprendizagem dos educandos, ensinando-os a interagir com a coletividade; refletir sobre a práxis e a produção de novos conhecimentos; conceber e realizar novos cursos em função da demanda; organizar pedagógica e didaticamente os conteúdos e adequá-los aos suportes técnicos que produzirão os materiais, definir as bases conceituais para desenvolver propostas pedagógicas sólidas e coerentes com as propostas de Educação a Distância. 


\section{EVOLUÇÃO DA EDUCAÇÃO A DISTÂNCIA}

A EaD não é um fenômeno novo, sendo um modo de ensinar e de aprender individualmente, que existe há, pelo menos, mais de cem anos (MOORE; KEARSLEY, 1996). Antes do aparecimento das comunicações via eletrônica, os educadores usavam a tecnologia impressa e os serviços postais, no que é conhecido como ensino por correspondência.

Com o aproximar do século XXI, revelaram-se alguns eventos que alteraram dramaticamente o cenário do ensino em todo o mundo. A emergência do conhecimento, como um dos fatores mais importantes a ser considerado para a prosperidade econômica das nações, foi um dos raros momentos de mudança, que segundo Toffler (1984) apud Pereira (2008), ocorreu apenas uma vez na história da humanidade, quando da transformação de um sistema econômico baseado na agricultura, para uma economia baseada na indústria. Uma transformação similar ocorre agora, à medida que a economia mundial assenta mais no conhecimento como fundamento para o aumento da produtividade (PRADO; VALENTE, 2002).

Deste modo, segundo Pereira (2008), a emergência da economia do conhecimento teve um duplo efeito no ensino: em primeiro lugar, as tecnologias de informação tiveram um profundo impacto nas práticas de ensino e da aprendizagem, evidenciadas pelo rápido crescimento de universidades virtuais e da expansão de práticas de $\mathrm{EaD}$; em segundo lugar, a indústria e o comércio veem-se a eles próprios como geradores e disseminadores de conhecimento, acabando com o semimonopólio do ensino superior na criação e divulgação de novos conhecimentos. A adoção da EaD conduziu, assim, a uma mudança social maior do que qualquer outro fator. 
A EaD é, tradicionalmente, definida como sendo uma forma de ensinar/aprender, com recurso, o material impresso, ou através de comunicação eletrônica dirigida a indivíduos comprometidos com o processo de aprendizagem, num lugar e num tempo diferentes daqueles em que estão o educador ou educadores. Todavia, a definição tradicional de $\mathrm{EaD}$ tem sofrido modificações, à medida que os desenvolvimentos tecnológicos mais recentes vão criando novos desafios aos educadores, no sentido de (re) conceptualizar a ideia de escola e de aprendizagem ao longo da vida

\section{O ADVENTO DA EDUCAÇÃO ONLINE}

A necessidade de atender à demanda de um novo paradigma educacional que congregasse as transformações advindas da sociedade plural atual, de ordens econômicas, políticas, culturais, científicas e tecnológicas, retomou antigas modalidades de ensino articuladas às novas possibilidades de uma sociedade tecnológica.

Nesta era digital, a sociedade se depara com múltiplas necessidades que se originam das relações entre seres que, imbuídos do desejo de adquirir mais informações e da necessidade de prosseguirem com sua formação "ao longo da vida", buscam caminhos para o fazer pedagógico em ambientes de aprendizagem online.

Nesse contexto, emerge uma série de iniciativas de cursos de especialização, extensão e graduação, pautados nas orientações da legislação vigente, que tem como preocupação básica a construção de novos espaços de aprendizagem via internet. Vale destacar a importância da portaria $n^{0}$ 2.253/2001 que permite as instituições de ensino utilizar um modelo híbrido de ensino nos seus cursos, ampliando os processos interativos nas propostas educacionais. 
As instituições de ensino superior poderão introduzir, na organização pedagógica e curricular de seus cursos superiores reconhecidos, a oferta de disciplinas que, em seu todo ou em parte, utilizem método não presencial, com base no artigo 81 da Lei no 9.394 , de 1996, e no disposto nesta Portaria.

As propostas educativas, que utilizam basicamente os meios telemáticos como a videoconferência, teleconferência e internet, são caracterizadas por Moran (2003) como Educação Online. Para o autor, a educação online permite diferentes desenhos de cursos, desde propostas totalmente virtuais, até perspectivas presenciais, potencializando as dinâmicas da sala de aula convencional.

Em relação à Educação a Distância, ele afirma que “(...) é um conceito mais amplo que o da educação online. Um curso por correspondência é à distância e não é online (...)”(MORAN, 2003, p.40). Este conceito vem sendo ressignificado por diferentes instituições sociais, com destaque às universidades, no sentido de proporcionar cursos de formação, bem como potencializar as discussões na educação presencial. A partir daí, existe uma diversidade de propostas, desde aquelas centradas no docente, e com pouca interação, até aquelas centradas no trabalho em grupo com bastante interatividade.

Moran (2003, p.40) define Educação Online como '(...) o conjunto de ações de ensino-aprendizagem desenvolvidas por meio de meios telemáticos, como a internet, a videoconferência e a teleconferência”.

Outro aspecto que Branco (2003) chama a atenção é em relação à compreensão do que seja Educação a Distância, que vem ampliar as concepções de ensino, antes confinadas à sala de aula. Nesse contexto, podemos reconhecer a importância da criação de comunidades virtuais de aprendizagem no compartilhamento de práticas, conheci- 
mentos, dinamizando a partilha de saberes e o crescimento de todos. A Educação Online se autoeco-organiza pela interatividade dos atores e suas interfaces tecnológicas, por exemplo: um fórum de discussão não se torna fórum sem a partilha de sentidos e os discursos dos seus interlocutores.

Para Santos (2005), além da autoaprendizagem, as interfaces dos ambientes virtuais de aprendizagem (AVA) permitem a interatividade e a aprendizagem colaborativa, ou seja, além de aprender com o material, o participante aprende na dialógica com outros sujeitos envolvidos - professores, tutores e principalmente outros cursistas - através de processos de comunicação síncronos e assíncronos (fórum de discussão, lista, chats, blogs, webfólios entre outros). Isso é revolucionário, inclusive quebra e transforma o conceito de distância.

Em educação online é importante garantir tanto atividades individuais quanto colaborativas e cooperativas. É preciso garantir aos sujeitos envolvidos vivências e diversos desafios sociocognitivos e político-culturais ao ato de pesquisar.

Dentre as diversas possibilidades abertas pelo paradigma digital, ocorre a liberação do polo da emissão que veio intensificar as várias relações sociais. Exemplo disso são os blogs, os chats, os fóruns de discussão, os e-mails, que potencializam a comunicação cada vez mais de forma interativa. Ressalta-se também a importância da conexão, que une os homens entre si através da máquina, numa constante troca de informações.

Contribuindo com a discussão sobre a Educação Online, Almeida (2003) reforça o seu uso via a internet, e a caracteriza como uma modalidade de educação, cuja comunicação ocorre de forma síncrona e assíncrona. Ressalta a autora que as interações entre os participantes podem ocorrer a partir de diferentes perspectivas comuni- 
cacionais, quais sejam: comunicação um-a-um, comunicação de umtodos e comunicação todos-todos. A terceira perspectiva traz como desafio a superação de propostas educativas hierárquicas e lineares, incluindo o debate plural de ideias e a possibilidade de intervenção e alteração na mensagem.

Almeida (2003, p.333) salienta que, na EaD em meio digital, pode-se observar que existe um foco central em determinado aspecto, diretamente relacionado com a abordagem educacional implícita, o qual pode ser:

- O material instrucional disponibilizado, cuja abordagem está centrada na informação fornecida por um tutorial ou livro eletrônico hipermediático. Essa abordagem se assemelha à autoinstrução e distribuição de materiais, chegando a dispensar a figura do professor;

- O professor, considerado o centro do processo educacional, o que indica abordagem centrada na instrução fornecida pelo professor, que recebe distintas denominações de acordo com a proposta do curso;

- O aluno, que aprende por si mesmo, em contato com os objetos disponibilizados no ambiente, realizando as atividades propostas a seu tempo e de seu espaço;

- As relações que podem se estabelecer entre todos os participantes evidenciando um processo educacional colaborativo no qual todos se comunicam com todos e podem produzir conhecimento, como ocorre nas comunidades virtuais colaborativas.

Para Santos (2005), o conceito de educação online está diretamente ligado ao desenvolvimento da cibercultura por possibilitar: a convergência de mídias, os encontros entre diferentes pessoas afastadas geograficamente, a vivência da interatividade, a aprendizagem colaborativa e os processos de comunicação síncronos e assíncronos. 
Para essa autora, todo esse potencial da educação online diferenciase das práticas convencionais de $\mathrm{EaD}$, que têm como foco principal a autoaprendizagem. A autora ressalta que essa perspectiva é reducionista, por não propiciar a dialógica entre os sujeitos, centrando-se apenas na resolução de atividades propostas no material do curso e a posterior entrega ao professor-tutor.

O grande desafio da Educação Online não está centrado unicamente na disponibilização de ambientes e interfaces gratuitas para a sua utilização nos diferentes espaços educativos, e sim na compreensão desses artefatos como potencializadores de práticas pedagógicas inovadoras que permitam aos aprendizes interações e coautoria na construção do conhecimento e do seu próprio processo de aprendizagem (SANTOS, 2005).

Cada vez mais sujeitos e grupos-sujeitos, empresas, organizações, enfim, espaços multirreferenciais de aprendizagem vêm lançando mão do conceito de Educação Online e promovendo a difusão cultural de suas ideias, potencializando a democratização da informação, da comunicação e da aprendizagem entre indivíduos geograficamente dispersos seja como elemento potencializador da educação presencial e ou da Educação a Distância. Os meios telemáticos mais utilizados nas atuais práticas de educação online são os ambientes virtuais de aprendizagem disponibilizados no ciberespaço.

\section{METODOLOGIA}

O conhecimento é algo que se constrói a partir das experiências vividas, o aprendizado resultante das dificuldades e das conquistas observadas no cotidiano. Para que esse conhecimento esteja acoplado às necessidades e demandas sociais torna-se indispensável a 
avaliação permanente e criativa do processo educacional e seus agentes transformadores, daí a importância da pesquisa, como aponta Demo:

\begin{abstract}
A aventura de construir conhecimento é tipicamente a aventura dos tempos modernos, num conluio surpreendente entre inteligência crítica e criativa humana e meios eletrônicos socializadores. Pesquisa adquire, assim, a condição de função básica do sistema educacional, em termos instrumentais, pervadindo não só as técnicas construtivas de conhecimento, mas igualmente o impulso crítico e criativo da educação emancipatória (DEMO, 1994, p.16).
\end{abstract}

Levando em conta a complexidade que envolve o fenômeno educacional, foi feita a opção pela Abordagem Qualitativa, por ser uma forma adequada para entender a natureza de um fenômeno social. "Os estudos que empregam uma metodologia qualitativa podem descrever a complexidade de determinado problema, analisar a interação de certas variáveis"(RICHARDSON, 1999, p.80).

Considerando os objetivos da nossa investigação, realizamos uma Pesquisa Exploratória que nos proporcionou maior familiaridade com o tema, a partir do levantamento bibliográfico que "é a base para as demais pesquisas e pode-se dizer que é uma constante na vida de quem se propõe a estudar”(FACHIN, 2001, p.125).

Sabe-se que a pesquisa bibliográfica é composta por mais de um momento, pois exige a localização dos exemplares a serem analisados, sua leitura e fichamento. Neste processo, foram classificados livros, dissertações, teses e artigos com temáticas relacionadas ao objeto de estudo. 


\section{FORMAÇÃO DE PROFESSORES UNIVERSITÁRIOS PARA EDUCAÇÃO ONLINE}

As transformações acarretadas pela rápida obsolescência da informação fazem com que as pessoas busquem uma formação permanente, uma atualização constante.

Para se implantar a EaD nas instituições educativas em nosso país, há que se rever a formação dos professores, para prepará -los ao desempenho das funções exigidas nesta modalidade de ensino. Exigindo, assim, constante atualização, ou seja, investimento permanente no processo de educação continuada para delinear o perfil necessário às exigências de sua formação profissional.

Deve-se assegurar, nos cursos de EaD, uma dupla qualidade, pedagógica e técnica, ou seja, um modelo mais integrado onde o professor deverá ser capaz de acompanhar e orientar todas as fases da produção. O uso mais intensivo dos meios tecnológicos de informação e comunicação torna o ensino mais complexo e exige a segmentação do ato de ensinar em múltiplas tarefas, sendo esta segmentação a característica principal da EaD.

É notório que o professor necessita se adaptar às novas exigências, precisa rever seus procedimentos e até mesmo a sua maneira de ensinar, aprender, pesquisar, analisar a ciência e de encarar a vida. Deverá assumir um papel de organizar, administrar e regular situação de aprendizagens, deixando de ser o dono do saber e o controlador da aprendizagem, para ser um mediador que estimula a curiosidade, o debate e a interação com os outros participantes do processo. No âmbito desta transição paradigmática, o professor desafia, orienta e acompanha o percurso e o resultado dos estudos, investigações e elaborações desenvolvidas pelo aluno, individual e coletivamente, pas- 
sando assim a construir ao invés de reproduzir, juntamente com os alunos, o conhecimento.

Espera-se que as decisões docentes promovam participação ativa, compartilhada e cooperativa; criem oportunidades variadas e flexíveis de negociação e construção de conhecimentos em ambientes presenciais e virtuais; utilizem um olhar prático-teórico aliado à força pedagógica da reflexão e observação da própria prática docente; exercitem metacognição e empatia nas tentativas de compreensão das necessidades de aprendizagem, facilidades, dificuldades e de modos de superá-las (FIORENTINI, 2009, p.137).

Para fazer frente a estas novas formas de ensinar, o professor passará a ter a necessidade constante de atualização, tanto no que se refere ao seu conteúdo de ensino, quanto em relação às novas metodologias de ensino e às novas tecnologias.

É fundamental levar os professores a se apropriarem criticamente dessas tecnologias, descobrindo as possibilidades de utilização que elas colocam à disposição da aprendizagem do aluno, favorecendo dessa forma o repensar do próprio ato de ensinar.

O documento criado pelo MEC, que aponta os Indicadores de Qualidade para cursos de graduação a distância, destaca que a instituição deve contar com educadores capazes de:

a) Estabelecer os fundamentos teóricos do projeto;

b) Selecionar e preparar todo o conteúdo curricular articulado a procedimentos e atividades pedagógicas;

c) Identificar os objetivos referentes a competências cognitivas, habilidades e atitudes;

d) Definir bibliografia, videografia, iconografia, audiografia etc., básicas e complementares;

e) Elaborar textos para programas a distância;

f) Apreciar avaliativamente o material didático antes e depois de ser impresso, videogravado, au- 
diogravado, etc., indicando correções e aperfeiçoamentos;

g) Motivar, orientar, acompanhar e avaliar os alunos;

h) Auto-avaliar-se continuamente como profissional participante do coletivo de um projeto de graduação a distância (BRASIL/MEC, 2000, p.06).

Segundo Moran (2001), o desafio que os profissionais que atuam no ensino superior irão enfrentar é motivar os estudantes, fase em que os alunos não precisam ir todos os dias à aula, a continuar aprendendo quando não estão em sala de aula. Educar a distância significa uma forma de ensino-aprendizagem onde ocorram trocas e não somente repasse de informação, que não deve ser simplesmente o ato de colocar conteúdo em uma página e depois cobrar atividade dos alunos. Estimular o aluno a aprender em ambientes virtuais é outro grande desafio pedagógico.

Ensinar em ambientes digitais e interativos de aprendizagem significa: organizar situações de aprendizagem, planejar e propor atividades; disponibilizar materiais de apoio com o uso de múltiplas mídias e linguagens; ter um professor que atue como mediador e orientador do aluno, procurando identificar suas representações de pensamento; fornecer informações relevantes, incentivar a busca de distintas fontes de informações e a realização de experimentações; provocar a reflexão sobre processos e produtos; favorecer a formalização de conceitos; propiciar a interaprendizagem e a aprendizagem significativa do aluno.

Nóvoa (2010) enuncia cinco teses a serem consideradas na formação de professores: conhecimento que se desenvolve a partir da prática voltada à aprendizagem; cultura profissional criada "dentro" da profissão, ou seja, aprendendo com os mais experientes; tato pedagógico que integra as distintas dimensões pessoais e as relações comu- 
nicativas com a profissão; trabalho em equipe e exercício coletivo no desenvolvimento do projeto pedagógico da escola; compromisso social que engloba os princípios e valores da inclusão social, da convivência com a diversidade cultural e da participação ativa na sociedade.

Ao trazer essas teses para a EaD online e inserir no bojo da formação do professor as TDIC, é importante considerar que o uso dessas tecnologias na formação envolve praticamente os mesmos elementos que qualquer processo formativo a distância (professores, alunos, estratégias didáticas, conteúdo, sistema de avaliação, etc.) e se diferencia na gestão desses elementos e na exploração das possibilidades pedagógicas das tecnologias de suporte, constituindo a EaD online como uma nova modalidade formativa (CASAMAYOR, 2008).

Trata-se de uma formação na práxis, que associa situações de formação e de trabalho por meio de um exercício reflexivo rigoroso, com o intuito de provocar a tomada de consciência sobre o processo de reculturação, reestruturação e reorganização temporal da prática (FULLAN, 1996 apud ALMEIDA, 2010). Essa formação não é simples, especialmente quando se trata de formação contínua de professores voltada para sua atuação em novos espaços, tempos e culturas, como é o caso da formação online integrada com a atuação na EaD online, a qual tem como norte as mudanças nas concepções, nos valores, nas crenças e nas práticas, que permitem ao professor formando mergulhar na nova cultura, reestruturar o pensamento de acordo com os novos modos de expressá-lo, interagir, construir conhecimento, trabalhar em colaboração e reorganizar o próprio tempo.

Dado que a formação do professor em ambiente online tem como finalidade prepará-lo para realizar o trabalho pedagógico mediatizado pelas linguagens veiculadas pelas TDIC, os conceitos de reculturação, reestruturação e reorganização dizem respeito à forma- 
ção em ambiente online, na qual o professor formando assuma diferentes papéis: no início de aluno, em seguida de planejador/designer de atividades online, seguido de mediador da aprendizagem do aluno em situação de ensino e aprendizagem online e de avaliador desses diferentes papéis.

A reflexão na ação e sobre a ação (SHÖN, 1992) deve permear todo o processo formativo e fornecer as bases para que o próprio formando possa compreender as mudanças nas suas concepções relacionadas ao aprender, planejar, ensinar e se comunicar em ambiente online. Porém, a reflexão não acontece ao acaso, ocorre quando são criadas condições com a intenção de provocar a introspecção, o olhar para as próprias representações, sentidos e valores que o professor atribui à sua experiência e à experiência do outro, em busca de compreender criticamente essa ação e propor transformações para a realização de novas ações mais apropriadas ao contexto de aprendizagem de seus alunos.

A análise dos caminhos epistemológicos percorridos pelo formando em seu processo de aprendizagem e o desenvolvimento de produções e dos registros digitais das interações favorecem ao professor em formação o reconhecimento das descrições, justificativas e explicações sobre as próprias experiências e possibilitam colocar em discussão os possíveis conflitos, contradições ou interpretações equivocadas, problematizá-los, refletir criticamente sobre eles e negociar novos significados. 


\section{CONSIDERAÇÕES FINAIS}

É fundamental levar os professores a se apropriarem criticamente dessas tecnologias, descobrindo as possibilidades de utilização que elas colocam à disposição da aprendizagem do aluno, favorecendo, dessa forma, o repensar do próprio ato de ensinar.

O trabalho docente online envolve o domínio do conteúdo de estudo, das tecnologias em uso e do processo pedagógico, no que se refere às concepções teóricas e metodológicas; a criação de estratégias didáticas que proporcionem a aprendizagem; a articulação do conteúdo com a tecnologia no desenvolvimento das atividades; a atitude de questionamento, diálogo, produção de conhecimento, colaboração e reflexão sobre a própria atuação; e a capacidade para trabalhar em grupo.

A formação docente online deve criar condições para que o professor possa desenvolver o domínio dessas tecnologias ao ponto de explorar confortavelmente suas funcionalidades e modos de operação para identificar suas contribuições pedagógicas para a interação multidirecional à autonomia do aluno na busca de informações, na regulação do tempo, no ritmo de estudo; acompanhar o caminho epistemológico do aluno, o trabalho em grupo colaborativo, os estudos de caso; ampliar o universo cultural do aprendiz; e provocar a transformação da prática pedagógica. Isso exige a superação de concepções de formação centradas no domínio de recursos e tecnologias ou na análise teórica sobre as tecnologias na sociedade e na educação e volta-se para a integração entre esses dois polos associados com a experiência em contexto online e com a reflexão sobre essa prática à luz de teorias que são articuladas com as experiências. 


\section{REFERÊNCIAS}

ALAVA, S. Ciberespaço e formações abertas: rumo a novas práticas educacionais. Porto Alegre: Artmed, 2002.

ALMEIDA, M. E. B. Educação a distância na internet: abordagens e contribuições dos ambientes digitais de aprendizagem. Educação e Pesquisa. In Revista da Faculdade de Educação da USP. São Paulo, v.29, n.2, 178p., jul./dez, 2003.

BEHAR, P. A. (Org.). Modelos pedagógicos em educação a distância. Porto Alegre: Artmed, 2009.

BELLONI, M. L. (org.). A formação na sociedade do espetáculo. São Paulo: Loyola, 2002.

BRANCO, A. C. A portaria no 2.253/2001 no contexto da evolução da educação a distância nas instituições de ensino superior do Brasil. In: SILVA, M. (Org.). Educação Online: teorias, práticas, legislação e formação corporativa. São Paulo: Loyola, 2003.

BRASIL. Indicadores de qualidade para cursos de graduação a distância. Brasília: MEC / Secretaria de Educação a Distância, 2000. Disponível em: http://www.mec.gov.br/seed/indicadores.shtm. Acesso em: 20 out. 2010.

Lei n. 9.394, de 20 de dezembro de 1996. Brasília: Presidência da República. Disponível em: http·//www.mec.gov.br/seed/ tvescola/ftp/leis/lein9394.doc. Acesso em: 20 out. 2010. 
CASTELLS, M. A sociedade em rede. São Paulo: Paz e Terra, 1999.

DEMO, P. Pesquisa e construção de conhecimento: metodologia científica no caminho de Habermas. Rio de Janeiro: Tempo Brasileiro, 1994.

FACHIN, O. Fundamentos de metodologia. 3. ed. São Paulo: Saraiva, 2001.

FIORENTINI, L. M. R. Aprender e ensinar com tecnologias, a distância e /ou em ambiente virtual de aprendizagem. In. Educação superior a distância: Comunidade de Trabalho e Aprendizagem em Rede (CTAR). Org. Souza, A. M. et al. Brasília: Universidade de Brasília, Faculdade de Educação, 2009.

FREIRE, P. Pedagogia da autonomia: saberes necessários à prática educativa. 15. ed. São Paulo: Paz e Terra, 1996. (Coleção Leitura)

GIL, A. C. Como elaborar projetos de pesquisa. São Paulo: Atlas, 1991.

GIL, A. C. Como elaborar projetos de pesquisa. 3. ed. São Paulo: Atlas, 1991.

LEVY, P. Cibercultura. Rio de Janeiro: Editora 34, 1999.

MOORE, M.; KEARSLEY, G. Educação a distância: uma visão integrada. São Paulo: Thomson Learning, 2007. 
MORAN, J. M. Contribuições para uma pedagogia da educação online. In. SILVA, M. (org.). Educação online: teorias, legislação, formação corporativa. São Paulo: Loyola, 2003.

NISKIER, A. Educação à distância: a tecnologia da esperança. 2. ed. São Paulo: Loyola, 2000.

NÓVOA, A. Profissão docente. In: Revista Educação, n. 154, fev. São Paulo, 2010. Disponível em: http://revistaeducacao.uol.com.br/textos.asp?codigo=12841. Acesso em: 10 nov. 2010 .

PEREIRA, E. W. Educação a distância, concepção e desenvolvimento. In.: Revista Linhas Críticas, v.9, n.17, p.197-212, jul/ dez. Brasília, 2003. Disponível em: http://www.fe.unb.br/linhascriticas/n17/educacao_a_distancia.html. Acesso em: 25 nov. 2010.

PORTO, M. Nova realidade digital tem reflexos nas relações de trabalho. Projeto Ponto-Futuro. Disponível em: http·//www.pontofuturo.org/home/modules.php. Acesso em: 07 out. 2010.

POZO, J. I. A sociedade da aprendizagem e o desafio de converter informação em conhecimento. In.: Pátio Revista Pedagógica, n.31, p.8-11, ago/out 2004.

PRADO, M. E. B. B.; VALENTE, J. A. A educação a distância possibilitando a formação do professor com base no ciclo da prática pedagógica. In: MORAES, M. C. Educação a distância: fundamentos e práticas. Campinas: SP, 2002. 
RICHARDSON, R. J. (Org.) Pesquisa social: métodos e técnicas. São Paulo: Atlas, 1999.

SANTOS, C. A. A expansão da educação superior rumo à expansão do capital: interfaces com a educação a distância. Tese (Doutorado). Universidade de São Paulo, 2008. Disponível em: www.teses.usp.br/ teses/disponiveis/48/.../TeseCatarinaAlmeidaSantos.pdf Acesso em: 27 mar. 2010.

SCHÖN, D. Formar professores como profissionais reflexivos. In: NÓVOA, A. (Coord.). Os professores e sua formação. Lisboa: Dom Quixote, 1992.

SILVA, M. Tecnologias e materiais didáticos nos cursos superiores a distância: promovendo a aprendizagem por meio da interatividade. In: Boletim do Salto para o Futuro. PGM 4 - Texto 1, 2003. (Série Educação a Distância na Universidade do Século XXI). Disponível em: http·/www.tvebrasil.com.br/SALTO/boletins2003/ edu/tetxt4. htm. Acesso em: 18 nov. 2010.

VALENTE, V. R. M. A formação de professores para o uso das tecnologias da informação e comunicação no processo pedagógico: caminhos percorridos pelo Núcleo de Educação e Tecnologias da rede municipal de ensino de Salvador. Dissertação - (Mestrado do Programa de Pós-Graduação em Educação e Contemporaneidade). Salvador: Universidade do Estado da Bahia, 2005. 